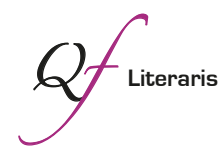

\title{
El Teatro de la Muerte de Tadeusz Kantor como espejo del siglo $\mathrm{XX}$
}

The Theatre of Death by Tadeusz Kantor as a reflection of the 20th century

\author{
Julia Nawrot
}

Universidad de Granada.jnawrot@ugr.es

Recibido: 04.07.2019. Aceptado: 04.08.2019

Resumen: El Teatro de la Muerte fue la última etapa de creación de Tadeusz Kantor, desde el inicio marcada por el interés de los muertos. En los cinco espectáculos, que se estrenaron desde 1975 hasta 1991, se pueden trazar los grandes hitos del siglo XX: en el escenario aparecen los soldados, sus generales, pero también las víctimas de los trágicos acontecimientos de las dos guerras mundiales. Todo ello a través de la mirada personal de Kantor, que convierte su pueblo natal, Wielopole Skrzyńskie, en la alegoría de Europa expuesta a continuos conflictos.

Palabras clave: Teatro de la Muerte; Tadeusz Kantor; Historia de Europa; siglo XX.

\begin{abstract}
The Theatre of Death was the last stage of Tadeusz Kantor's theatre production, which was marked by the interest in the dead from its beginning. The great milestones of the twentieth century can be traced in all the five performances (from 1975 to 1991). On the stage appear soldiers and their generals, but also the victims of the tragic events of the two World Wars. All this is shown through Kantor's personal view, who turns his hometown, Wielopole Skrzyńskie, into the allegory of Europe exposed to continuous conflicts.
\end{abstract}

Keywords: The Theatre of Death; Tadeusz Kantor; European History; Twentieth century.

\) Nawrot, Julia. 2019. "El Teatro de la Muerte de Tadeusz Kantor como espejo del siglo XX". Quaderns de Filologia: Estudis Literaris XXIV: 183-196. doi: 10.7203/qdfed.24.16339 

El arte es

la respuesta

a la realidad

T. Kantor ${ }^{1}$

Tadeusz Kantor, como artista sensible a los acontecimientos históricos y sociales que lo rodeaban, reflejó en su arte las mayores preocupaciones de la realidad en la que le tocó vivir y trabajar. Su vida y su trayectoria artística abarcaron buena parte del siglo XX: nació durante la Primera Guerra Mundial y murió poco más de un año después de la caída del Muro de Berlín, tras haber dedicado más de cincuenta años al teatro. La última etapa de creación teatral de Kantor, el Teatro de la Muerte, es la más larga de todas y comprende cinco espectáculos a lo largo de quince años, lo que supone una ruptura con las etapas anteriores (Nawrot, 2018). Desde el estreno de La clase muerta en 1975, que marcó el inicio de este período, hasta Hoy es mi cumpleaños -puesto en escena por la compañía Cricot 2 ya después de la desaparición de su director y maestro-, se abandonó el uso de textos dramáticos previos ${ }^{2}$, y se puso el foco en los recuerdos del propio Kantor y en la memoria de los tiempos pasados.

La idea del primer montaje del Teatro de la Muerte había surgido cuando Kantor vio en un pueblo una pobre y abandonada escuela de principios del siglo XX (Kantor, 2010b: 141).

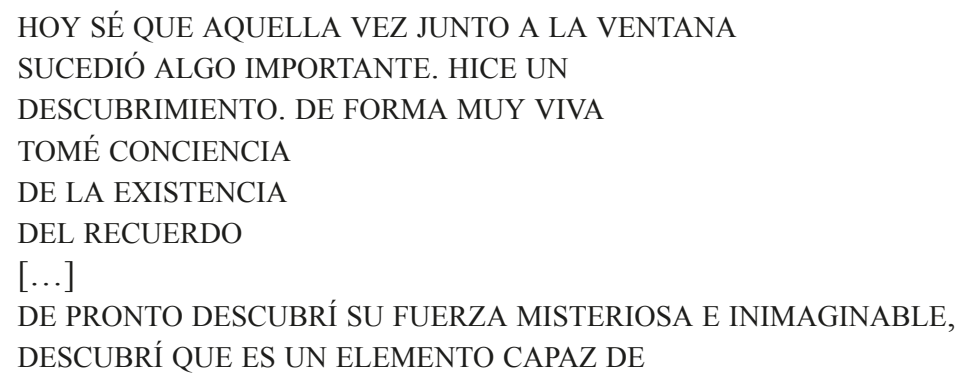

\footnotetext{
${ }^{1}$ Las traducciones de todas las citas provenientes de las referencias bibliográficas en polaco, inglés y francés son nuestras.

${ }^{2}$ Como apunta Magda Romanska (2012: 188), durante los primeros 20 años de su existencia Cricot 2 "jugaba con Witkiewicz" utilizando con gran libertad los textos dramáticos de este autor en las puestas en escena correspondientes a cada una de las etapas previas al Teatro de la Muerte.
} 
DESTRUIR Y CREAR,

QUE ES EL PRINCIPIO DE LA CREACIÓN, QUE ESTÁ EN LA GÉNESIS DEL ARTE.

(Kantor, 2010b: 141-142)

La clase muerta gira en torno de la memoria de la infancia reconstruida mediante el desdoblamiento entre los personajes llamados "participantes de la sesión", unos viejecitos interpretados por los actores de la compañía, que vuelven a los bancos de su antigua clase de escuela, y unos maniquíes, que los representan a ellos mismos en el pasado. Se trata de unos individuos muy ambiguos, compuestos por las experiencias vividas, sus recuerdos, sus sueños o sus deseos, que en el curso de la acción escénica cambian y se descomponen (Kantor, 2005a: 32; Kantor, 2010a: 31-32). Cada uno de ellos repite una y otra vez los mismos movimientos, recreando las situaciones propias de una clase como una lección de gramática, las muecas de los alumnos o el interrogatorio del profesor. Los personajes están atrapados en esta incesante repetición, que Romanska (2012: 200) define como una trampa de un gesto postraumático en la que está encerrada toda la generación de Kantor:

[C]aminando en círculos, los alumnos no pueden escapar de su vida ni de su muerte: no pueden deshacer lo que ha sucedido. Sólo pueden repetir, de forma compulsiva y trágica, los movimientos y los gestos de las clases de su infancia, como si tuvieran la esperanza de que, haciéndolo, tendrán una oportunidad más (Romanska, 2012: 200).

Entre todos los personajes de La clase muerta hay dos figuras especialmente significativas en el desarrollo de la acción escénica: la Mujer de la limpieza y el Bedel. La primera, cuyas entradas en el escenario causan terror entre los demás personajes, dado que -aparte de su función nominal- encarna también a la muerte, protagoniza una secuencia titulada "Periódico de año 1914". Tras ojear un amarillento diario, anuncia con "una extraña satisfacción" (Kantor, 2010a: 101) el comienzo de la Primera Guerra Mundial:

En Sarajevo...

un serbio llamado Princip Gavrilo

ha asesinado al heredero al trono, el Archiduque Fernando 
... junto con su esposa...

$[\ldots]$

... ¡PUES TENEMOS MONTADA

LA GUERRA!

(Kantor, 2010a: 100)

A estas palabras de la Mujer de la limpieza reacciona el personaje del Bedel que hasta ahora permanecía completamente inmóvil, más parecido a una figura de cera que a una persona viva: se levanta con visible dificultad, se pone en posición de firmes y canta el himno austriaco, tras lo cual abandona el escenario.

En estas dos pequeñas escenas de la primera parte de La clase muerta la memoria personal de Kantor entronca con la memoria colectiva de un pueblo entero, indudablemente marcada por la Primera Guerra Mundial. En el escenario, mediante acciones de los personajes de la obra, los recuerdos cobran vida y la intrahistoria del artista de pronto se convierte en la gran Historia de la Europa del siglo XX.

Todo el espectáculo está atravesado por los acontecimientos históricos del primer gran conflicto bélico mundial que en la segunda parte se personifica en el Soldado de la Primera Guerra Mundial. Este personaje, que al inicio aparece mudo entre los demás alumnos envejecidos sentados en los bancos de la escuela, vuelve a escena tras la secuencia titulada "El responso", i. e. una larga y tediosa retahíla de nombres de difuntos sacados de los registros parroquiales. La rememoración de los muertos termina con la entrada del Soldado "con un puñado de esquelas que / empieza a repartir sistemáticamente, y / luego las lanza como si fueran octavillas" (Kantor, 2010a: 174). Su gesto, que por un lado se inscribe en el desarrollo lineal de la acción escénica anterior, en el segundo plano simboliza la difusión de las trágicas noticias referidas por todos los periódicos: el asesinato del archiduque Fernando, que hizo tambalear al orden europeo de la época.

La Primera Guerra Mundial supuso una ruptura con la armonía del Imperio austrohúngaro, que en aquellos tiempos reinó también en la región polaca de Galitzia donde nació Tadeusz Kantor. Fue un hecho que marcó de forma profunda al artista, que lo rememoraba constantemente en su teatro. 
La nostalgia por los tiempos pasados de la monarquía se personificó en la figura del Bedel de La clase muerta (Stanisław Michno) y del Repartidor de Periódicos [de Hoy es mi cumpleaños] (Lech Stangret) que gritando la frase: 'Ayer, en Sarajevo, el serbio Gavrilo Princip asesinó al Archiduque Fernando', anunciaba la caída de un mundo ordenado (Święcicki, 2007: 310).

Las secuencias del anuncio del estallido del gran conflicto bélico europeo y el himno austriaco por primera vez aparecieron en La clase muerta, para posteriormente entrar, aunque con algunas modificaciones, en la última puesta en escena de Cricot 2, Hoy es mi cumpleaños (Zajączkowski, 2008a: 00:25:37-00:27:28). A través de este tipo de escenas, la memoria del pueblo natal de Kantor -Wielopole Skrzyńskie-, en el amplio marco de la gran Historia, se convirtió en uno de los temas clave el Teatro de la Muerte.

El espectáculo de 1980 Wielopole, Wielopole, incluso tomó su título de esta pequeña aldea del sur de Polonia. Este segundo montaje de la etapa del Teatro de la Muerte está completamente atravesado por los hechos relacionados con los conflictos bélicos del siglo XX, y los Reclutas de la Primera Guerra Mundial son sus principales protagonistas. Desde el inicio, y durante varios minutos (Zajączkowski, 2008b: 00:03:2400:00:12:57), los nueve Reclutas están presentes en la parte derecha del escenario, completamente inmóviles, como si estuvieran inmortalizados en la vieja fotografía de 1914 que le sirvió a Kantor de inspiración.

Según las palabras del artista, "las fotografías de los RECLUTAS son recuerdos de MUERTOS. / Fueron elegidos y designados por la muerte" (Kantor, 1981: 22). Curiosamente, los Reclutas de Wielopole, Wielopole-que por su completa inacción parecían figuras de cera- empiezan a moverse cuando el personaje llamado la Viuda del fotógrafo los apunta con su antigua cámara de fuelle instalada sobre un trípode con ruedas. Al son de lo que será el principal tema musical de este montaje, la Marcha de la Infantería Gris ${ }^{3}$, los reclutas se agitan inquietos. Sus movimientos, más que humanos, son más bien de muñecos rotos, maniquíes que carecen de voluntad propia y no tienen fuerza interior para levantarse o hablar. La Viuda del fotógrafo corrige sus posiciones y alisa sus uniformes, obligándoles a estar quietos para que la toma salga

\footnotetext{
${ }^{3}$ Se trata de una conocida canción patriótica de las Legiones Polacas, las fuerzas armadas polacas creadas en la región de Galitzia durante la Primera Guerra Mundial.
} 
bien. Pero cuando ella misma se coloca detrás de la cámara apuntándolos con el objetivo, en vez de sacar una foto de los Reclutas, empieza a dispararles, fusilándolos con la metralleta en la que de pronto se ha convertido su cámara de fuelle. La tragedia de los soldados destinados a morir en las trincheras de la Primera Guerra Mundial se anuncia desde el momento en que aparecen en la foto.

Como indica Roland Barthes en su conocido ensayo, la imagen convierte en objetos a los que antaño fueron sujetos vivos (Barthes, 2009: 34). En Wielopole, Wielopole los Reclutas carecen de rasgos personales, todos se parecen entre sí: "llevan uniformes descoloridos y sus caras tienen color de tierra [porque] han sido exhumados" (Kott, 1987: 3). Pertenecen al mundo de los muertos, pero han sido traídos al escenario a través de la memoria de Kantor que los convirtió en modelos para ser actor.

Cabe destacar que al artista polaco no le llamaba la atención la figura del soldado individual, aunque entre los Reclutas incluyó al personaje de su Padre Marian, sino que se interesó por el ejército como una masa, un grupo homogéneo y homogeneizado. Como afirmó en una entrevista:

El ejército. Dos rasgos, los más característicos y los más profundos de la esencia de lo militar, se identifican con lo que desde hace siglos están marcando al actor: el uno es la OPOSICIÓN entre nosotros y los CIVILES-ESPECTADORES, una oposición tan grande que la barrera así creada provoca la sensación de la IMPOSIBILIDAD DE VENCERLA, una sensación que se experimenta sólo en una pesadilla.

El otro es la espantosa impresión (que también se siente en una alucinación) de que esa OPOSICIÓN se refiere a la misma especie que la nuestra, es decir, a NOSOTROS MISMOS, de que precisamente NOSOTROS somos esos EXTRAÑOS, esos MUERTOS, de que es nuestra imagen con la que debemos IDENTIFICARNOS. Una semejanza palpable: EL EJÉRCITO Y EL ACTOR (Gieraczyński, 1981: 112).

Pero la presencia de los soldados en el escenario no es tan solo un recurso teatral que usa Kantor para subrayar la autonomía de la realidad escénica frente a los espectadores, sino que es una manera de introducir en sus espectáculos algunos elementos cruciales de la historia del siglo XX. Esta "nueva esfera psicológica en la interpretación del actor" (Kantor, 1997: 23), que consiste en la recreación de la condición de los muertos por personajes vivos, hace que "EL PASADO [...] SE DESLIZA 
SECRETAMENTE / EN EL PRESENTE" (Kantor, 1997: 23). De esta forma, se prolonga la idea que subyace en todo el Teatro de la Muerte, según la cual la vida se puede expresar solamente a través de la muerte o la ausencia de vida (Pleśniarowicz, 2005: 5; Kantor, 2010a: 42-43).

Los Reclutas de Wielopole, Wielopole muestran asimismo la cara cruel de la Primera Guerra Mundial. En sus irrupciones en el escenario ejercen violencia en los demás personajes, como en la secuencia en la que se divierten con el maniquí de la Madre Helka o cuando realizan los "ejercicios militares para infringir la muerte" (Kantor, 2010a: 305-306), hundiendo sus bayonetas en el cuerpo del Tío Józek-Cura. En una de las secuencias siguientes titulada "De nuevo «ESTE SEÑOR»", los mismos personajes se convierten en los soldados adiestrados por uno de los oficiales nazis más temidos durante la Segunda Guerra Mundial, Heinrich Himmler. Este, sin embargo, no aparece señalado de forma explícita como tal, puesto que Kantor "no considera apropiado mencionar el nombre que causó temor en todos los guetos del mundo" (2005a: 195). Por ello el personaje se presenta bajo el alias de Ya se sabe quién, pero su atuendo es inconfundible: "Botas altas, un abrigo militar con un corte bien conocido y una gorra [también] conocida con la parte delantera alta. Sólo falta la calavera" (Kantor, 2005a: 195). De nuevo, Wielopole, Wielopole, a través de los clichés de la memoria, evoca algunos de los hitos más trágicos de la Europa del siglo XX.

El horror de la Segunda Guerra Mundial se materializa también en las figuras de los soldados nazis del espectáculo kantoriano titulado $\mathrm{Ja}$ más volveré aqui (1988). En este montaje, que recoge todas las ideas anteriores de Kantor convirtiéndose en una especie de su testamento teatral, aparece un grupo de personajes llamados Violinistas de acero que con paso firme cruzan el escenario persiguiendo al personaje llamado Rabino de Wielopole. La "espeluznante marcha de los espectros" (Kantor, 2010b: 117), con sus movimientos impasibles a la vez que amenazadores, evoca la tragedia del Holocausto que había aparecido ya en una de las escenas finales de Wielopole, Wielopole, cuando el Rabino sufría "su posterior (mucho más tardío) destino" (Kantor, 2010a: 244). En la secuencia del espectáculo de 1980, todos los personajes, incluidos los Reclutas, efectúan una ronda alrededor de la figura del judío que, desesperado, canta una triste canción en yiddish (Zajączkowski, 2008b: 01:08:50-01:09:27). "Pero los SOLDADOS ya están hartos de estos. / [...] el pelotón de ejecución hace una descarga / y el pobre RABINEK cae al 
suelo" (Kantor, 2010a: 325). El carácter semifestivo del desfile de los personajes de Wielopole, Wielopole desentona con la aflicción del Rabino y supone un profundo contraste con el final que éste sufre al ser fusilado. La escena se repite una y otra vez, hasta que Kantor señala ${ }^{4}$ su final y los personajes desparecen en el fondo del escenario. Es un momento muy emotivo, en el que todo el universo kantoriano se detiene para poner foco en el genocidio perpetrado por los nazis durante la Segunda Guerra Mundial.

También en el último espectáculo de Cricot 2 se hace referencia a los fusilamientos en masa que se cometieron en todos los territorios ocupados por la Alemania nazi. En Hoy es mi cumpleaños (1991) Kantor introduce la figura de Jonasz Stern, un artista polaco y su amigo personal, que sobrevivió en 1943 a la ejecución de los judíos del gueto de Leópolis al caer a la fosa común y esconderse entre los cuerpos de las otras víctimas. El conmovedor testimonio en que Stern narra cómo logró salvarse de su propia muerte se reproduce desde una grabación que acompaña la entrada del personaje en el escenario. La voz que oyen los espectadores es auténtica y le confiere a la escena un mayor sentimiento de realidad, reforzado también por la apariencia externa del actor que lo interpreta $^{5}$. El personaje de Stern en Hoy es mi cumpleaños tiene un aspecto propio del imaginario de los prisioneros de campos de concentración nazis: es muy flaco, viste con una camisa blanca que apenas cubre su cuerpo y en el brazo izquierdo lleva un brazalete con la estrella de David. Emerge del mundo de los muertos para contar su historia personal, que a la vez simboliza el destino que padeció todo el pueblo judío. El exterminio masivo de judíos, el mayor crimen del fascismo alemán de la Segunda Guerra Mundial, es uno de los temas que estuvo presente en todos los montajes del Teatro de la Muerte, aunque de forma más explícita se materializó en el espectáculo estrenado en 1991.

Pero el nazismo no es el único régimen totalitario cuyos ecos se encuentran en Hoy es mi cumpleaños. En su último montaje Kantor quiso rendirle homenaje a Vsévolod Meyerhold. Este director ruso, uno de los máximos representantes de la vanguardia teatral, fue encarcelado, torturado y finalmente fusilado en el marco de las purgas estalinistas

\footnotetext{
${ }^{4}$ Tadeusz Kantor "siempre [estaba] presente en sus espectáculos, desempeñando diversos roles, nunca claramente determinados: director de escena, actor, mero observador... Indefinido pero indispensable" (Nawrot, 2015: 216).

${ }^{5}$ El personaje de Jonasz Stern fue interpretado por Zbigniew Gostomski.
} 
de finales de los años treinta del siglo XX. Kantor presenta en escena el momento en que Meyerhold es capturado por los soldados soviéticos del NKVD y desde los altavoces se oye la carta que escribió desde la cárcel a Viacheslav Molotov, el entonces presidente del Consejo de Comisarios del Pueblo. En su misiva ${ }^{6}$ Meyerhold describía el proceso de torturas a las que fue sometido y se retractaba de las confesiones autoinculpatorias que le fueron arrancadas. Pero aunque pidiera clemencia al propio jefe de Estado de la URSS esta nunca le fue concedida.

El totalitarismo soviético fue implacable con sus prisioneros, como también demuestra otro personaje del Teatro de la Muerte, el Tío Stasio. Por primera vez Kantor lo incluye en Wielopole, Wielopole, aclarando que se trata de un Deportado que vuelve a su pueblo natal desde Siberia. Este personaje "resulta ser al final un simple SOLDADO ERRANTE" (Kantor, 2010a: 279), en el que "se ha posado ese halo de luto" (Kantor, 2010a: 279), propio de los prisioneros de guerra que pasaron por el lager. Viste como un pordiosero, con un abrigo de uniforme militar desgastado, y lleva consigo un simple organillo. Lo acciona con una manivela para hacer sonar el melancólico villancico proveniente del Scherzo en Si menor de Chopin, pero distorsionado, lo que le confiere un aire aún más trágico. "El DEPORTADO-SOLDADO ERRANTE (TÍO STASIO) aparece siempre en los momentos difíciles" (Kantor, 2010a: 315) reza el título de una de las secuencias de Wielopole, Wielopole, ya que en el espectáculo el personaje marca los momentos cruciales de la acción escénica, como la (falsa) noticia sobre la muerte del Padre Marian; o la crucifixión de Adaś, el más joven de la familia que fue llamado al frente de la Primera Guerra Mundial, donde murió. El cuerpo de esta inocente víctima es devuelto a la Pequeña Habitación de la Infancia (Kantor, 2010a: 245-249) donde se desarrolla la acción de Wielopole, Wielopole. De forma simbólica Adaś regresa al seno familiar para ser enterrado, y sus restos son colocados inertes junto a un montículo de tierra con una cruz de madera cerca de la boca del escenario.

Las tumbas pueblan el Teatro de la Muerte. Según las palabras de Jan Kott, "[1] as tumbas son las huellas de la historia. Las del siglo XX son fosas comunes" (Kott, 1987: 4). A partir de Wielopole, Wielopole, las cruces que las evocan se convierten en un elemento recurrente de los

\footnotetext{
${ }^{6}$ En el espectáculo se utilizó la grabación de la versión original en ruso de la carta de Meyerhold a Molotov leída por E. Nirman.
} 
montajes kantorianos. Simbolizan a los soldados caídos durante las dos Grandes Guerras, y a veces incluso configuran en el espacio escénico, como en iQue revienten los artistas! (1985) donde el lugar teatral es un cementerio, "el MUNDO DE LOS MUERTOS, la ETERNIDAD" (Kantor, 2005b: 29). Allí de pronto se personifica el Mariscal Piłsudski, representado por el personaje llamado Quien todos sabemos ${ }^{7}$, que viene rodeado de sus generales. "No se sabe si es un desfile de los vencedores, / o si la procesión funeraria del célebre de la nación" (Kantor, 2005b: 35). Su solemne entrada encima de un esqueleto de caballo se produce al son de una marcha militar de la Primera Guerra Mundial, Nosotros, la primera brigada. Sin embargo, más adelante el personaje entona una canción de la misma época, pero mucho más melancólica, que reza: "Me llevarán de las trincheras con bayonetas / [...] me besará la muerte / pero no tú".

Porque la guerra en los espectáculos de Cricot 2 no tiene un aspecto heroico, sino trágico. De ahí que en Hoy es mi cumpleaños se muestren las fosas comunes, personificadas no sólo en la figura de Jonasz Stern, sino también en los cuerpos de los soldados desconocidos, sumidos en el anonimato mediante los emballages (Zajączkowski, 2008a: 00:28:47-00:33:50).

Para Kantor, el siglo pasado fue un período de grandes cataclismos de la historia e intento en vano de proteger al individuo contra la acción destructiva de los totalitarismos. Contra estas amenazas sólo el arte pudo ser el lugar de salvación del ser humano, de la construcción de la autonomía de su yo (Święcicki, 2007: 311).

En su ensayo titulado "Salvar del olvido" (Kantor, 2005b: 125-130), el artista polaco expresó su desprecio hacia la gran Historia, con sus movimientos, ideologías, guerras y crímenes, a la que contrapuso la "Pequeña, / Pobre, / Vulnerable, / pero maravillosa / Historia / de una vida / individual / humana" (Kantor, 2005b: 126). Fueron su propia vida y su propia experiencia las que le permitieron construir los espectáculos del Teatro de la Muerte, sirviéndose también de los personajes

\footnotetext{
${ }^{7}$ A pesar de la similitud de su nombre, el personaje de Quien todos sabemos de ; Que revienten los artistas! no es el mismo que el de Ya se sabe quién de Wielopole, Wielopole. Aunque, igual que en el caso de Himmler, el nombre del Mariscal Piłsudski "no será pronunciado" (Kantor, 2005b: 33).
} 
llamados los Queridos ausentes (Kantor, 2005a: 2009; Kantor, 2005b: 230; Kantor, 2010a: 248). Se trataba de sus familiares, evocados por la memoria y llamados al escenario, donde se cruzaban con varios personajes del trágico siglo XX, lleno de los conflictos bélicos. Ya en Wielopole, Wielopole

...el destino de la familia del artista cobró el carácter universal. La aldea de Galitzia se convirtió en la alegoría de Europa expuesta a continuos conflictos. En el espectáculo la Familia intenta volver a su vida normal tras las repetidas marchas del ejército. Sin embargo estos intentos son inútiles. Resulta que la huida hacia lo privado no protege contra los cataclismos de la historia (Święcicki, 2007: 294).

La memoria individual de Kantor, a través de su teatro, se convierte en la memoria histórica (Walker, 2007: 21). En todos los espectáculos del Teatro de la Muerte, desde La clase muerta hasta Hoy es mi cumpleaños, se pueden trazar los grandes hitos del siglo XX, con sus acontecimientos más trágicos: fusilamientos en masa, fosas comunes, o campos de exterminio nazi. En sus conmovedoras puestas en escena Kantor rescata del olvido a los muertos de la Primera y la Segunda Guerra Mundial, utilizando simbología entendida en todos los países en los que Cricot 2 presentó sus montajes. Su objetivo no fue en ningún momento sermonear a los espectadores, sino buscar su complicidad y emocionarlos con las escenas que se sucedían sin cesar. La preocupación de Kantor por los muertos se hizo patente desde el Manifiesto del Teatro de la Muerte (Kantor, 2005a: 13-22; Kantor, 2010b: 123-137), a partir del cual -con pocas pinceladas- introdujo en sus espectáculos múltiples referencias a los protagonistas de la Historia del siglo XX.

Debido a su fragmentarismo, es muy difícil explicar el teatro kantoriano (Urdeix, 1983: 34) que se sirve de lo que el artista polaco denominaba los clichés de la memoria. Entre ellos encontramos "la memoria común: la memoria de la guerra, la memoria de la crueldad, la memoria de los muertos" (Kott, 2005: 38), aunque no sea de forma demasiado explícita $\mathrm{y}$ directa.

Al igual que el Kadish, que nunca hace referencia directa a lo que se refiere-la muerte; Kantor [...] nunca hace referencia directa a lo que se refiere- el Holocausto. Más bien, es la sensación del luto por un mundo desaparecido, para siempre, lo que impregna los espectáculos de Kantor 
a través de las imágenes reconstruidas a partir de memoria (Romanska, 2012: 259).

Tadeusz Kantor "cultiva la memoria como consecuencia de la imaginación y la única voz de acceso a una verdad de orden superior" (Lachaise, 2016), y su Teatro de la Muerte adquiere un valor de testimonio y espejo del siglo XX.

\section{Bibliografía}

Barthes, Roland. 2009. La cámara lúcida. Traducción de Joaquim Sala-Sanahuja. Barcelona: Paidós.

Gieraczyński, Bogdan. 1981. La personificación de la muerte en el arte de Kantor. Nueva Estafeta 37, diciembre 1981: 111-115.

Kantor, Tadeusz .1981. Tadeusz Kantor escribe sobre Wielopole, Wielopole. Pipirijaina 19-20, octubre 1981: 18-23.

Kantor, Tadeusz. 1987. El Teatro de la Muerte. Selección y presentación de Denis Bablet. Prólogo a la edición en español de Kive Staiff. Traducción de Graciela Isnardi. Buenos Aires: Ediciones de la Flor.

Kantor, Tadeusz. 1997. La memoria como proceso de creación. En Skipp, Tom (coord.) Tadeusz Kantor. La escena de la memoria (catálogo de exposición). Madrid/Barcelona: Fundación Arte y Tecnología / Fundació Caixa de Catalunya. Traducciones del polaco: Fernando Presa González y Agnieszka Matyjaszczyk Grenda; traducción de los textos de Kantor: Encarna Castejón. Madrid: T. F. Artes Gráficas, S. A., 19-25.

Kantor, Tadeusz. 2005a. Pisma. Tom II. Teatr Śmierci. Teksty z lat 1975-1984. [Obras. Tomo II. El Teatro de la Muerte. Textos de los años 1975-1984]. Krzysztof Pleśniarowicz (ed.). Wrocław/Cracovia: Ossolineum/Cricoteka.

Kantor, Tadeusz. 2005b. Pisma. Tom III. Dalej już nic... Teksty z lat 1985-1990. [Obras. Tomo II. En adelante nada más... Textos de los años 19851990]. Krzysztof Pleśniarowicz (ed.). Wrocław/Cracovia: Ossolineum/ Cricoteka.

Kantor, Tadeusz. 2010a. La clase muerta. Wielopole, Wielopole. Traducción y notas: Fernando Bravo García. Barcelona: Alba Editorial.

Kantor, Tadeusz. 2010b. Teatro de la muerte y otros ensayos (1944-1989). Selección y traducción: Katarzyna Olszewska Sonnenberg. Barcelona: Alba Editorial.

Kott, Jan. 1987. Jan Kott escribe sobre Tadeusz Kantor. El Público 43, abril 1987: 3-4. 
Kott, Jan. 2005. Kadysz. Strony o Tadeuszu Kantorze. [Kadish. Páginas sobre Tadeusz Kantor]. Gdańsk: Słowo/obraz terytoria.

Lachaise, Virginie. 2016. Le Théâtre de la mort de Tadeusz Kantor: un "gué secret" entre les vivants et les morts. Conserveries mémorielles, \#18 | 2016. http://journals.openedition.org/cm/2190 [Acceso 30/09/2019].

Nawrot, Julia. 2015. Tadeusz Kantor en el centenario de su nacimiento. Impossibilia. Revista Internacional de estudios literarios 9: 210-218. http:// ojs.impossibilia.org/index.php/impossibilia/article/view/12 [Acceso 22/05/2019].

Nawrot, Julia. 2018. Dramaturgia espectacular. Enfoque teórico de Tadeusz Kantor. Signa. Revista de la Asociación Española de Semiótica 27: 835-856. https://doi.org/10.5944/signa.vol27.2018.19107

Pleśniarowicz, Krzysztof. 2005. Wstęp. [Introducción] En Kantor, Tadeusz Pisma. Tom II. Teatr Śmierci. Teksty z lat 1975-1984. [Obras. Tomo II. El Teatro de la Muerte. Textos de los años 1975-1984]. Krzysztof Pleśniarowicz (ed.). Wrocław/Cracovia: Ossolineum/Cricoteka, 5-6.

Romanska, Magda. 2012. The Post-traumatic Theatre of Grotowski and Kantor. History and Holocaust in 'Akropolis' and 'Dead Class'. Anthem Press.

Święcicki, Klaudiusz. 2007. Historia w teatrze Tadeusza Kantora. [Historia en el teatro de Tadeusz Kantor]. Poznań: Wydawnictwo Poznańskie.

Urdeix, Josep. 1983. La clase muerta. Situación límite. El Correo Catalán 11 de marzo de 1983: 34.

Walker, Beatriz. 2007. Benedetti, Rosencof, Varela: El teatro como guardián de la memoria colectiva. Buenos Aires: Corregidor.

Zajączkowski, Stanisław. 2008a. Dziś sq moje urodziny. [Hoy es mi cumpleaños]. Cracovia: Cricoteka.

Zajączkowski, Stanisław. 2008b. Wielopole, Wielopole. Cracovia: Cricoteka. 